\title{
DESENVOLVIMENTO DE ENSAIO DE FADIGA DE UM COMPONENTE AUTOMOTIVO COM LUBRIFICAÇÃO
}

\author{
José Gabriel Vicente $^{1}$, Taeko Yonamine Fukuhara ${ }^{1}$, Amilton Sinátora ${ }^{2}$, Almir Atoette $^{3}$ e José \\ Martinho Pelacani Jr. ${ }^{3}$ \\ ${ }^{1}$ Instituto de Pesquisas Tecnológicas do Estado de São Paulo S.A.-IPT \\ ${ }^{2}$ Universidade de São Paulo-USP \\ ${ }^{3}$ ThyssenKrupp Metalúrgica Campo Limpo
}

E-mails: gvicente@ipt.br, taekoyf@ipt.br, sinatora@usp.br, almir.atoatte@,thyssenkrupp.com, jose.pelacani@thyssenkrupp.com

\section{RESUMO}

O desenvolvimento de componentes automotivos demanda diversos testes de validação sendo um deles o de fadiga. Para o projeto de uma junta automotiva, robusta do ponto de vista mecânico-tribológico, foi necessária a concepção de um teste especial de fadiga com avaliação de desgaste. O trabalho foi realizado em parceria do IPT com a ThyssenKrupp. Os modelos tridimensionais foram validados estruturalmente em simulação por elementos finitos. Em seguida, o ensaio de fadiga em laboratório foi executado utilizando os parâmetros dos cálculos numéricos. Neste ensaio foi empregado um sistema de lubrificação dedicado juntamente com um sistema de fixação que correlaciona o componente ensaiado com sua real aplicação. Em intervalos regulares as superfícies da junta foram avaliadas através de medições tribológicas e dimensionais com relação à evolução do desgaste.

\section{INTRODUÇÃO}

O projeto da junta automotiva analisada é diferenciado, uma vez que outros componentes normalmente utilizados para funções similares têm geometrias diferentes. Esta junta simula uma biela e um pistão, porém sem pino de articulação. A biela é articulada diretamente no pistão. $\mathrm{O}$ ensaio de fadiga desenvolvido está direcionado ao estudo da articulação na junta. $\mathrm{O}$ objetivo foi testar uma biela onde as duas extremidades simulavam a geometria da parte superior da biela que tem articulação com o pistão. O intuito foi duplicar a geração de dados por ensaio. Uma análise por elementos finitos foi feita com os parâmetros iguais aos que seriam utilizados no ensaio. $\mathrm{O}$ conjunto ensaiado é formado por duas garras, uma superior e outra inferior, conectadas por uma "biela" com extremidades similares. Após a aplicação dos ciclos de fadiga em controle de força os registros da condição de desgaste da superfície foram realizados. Foi fotografada em lupa estereoscópica a condição superficial e também foi medida a rugosidade nas superfícies em contato das articulações biela/garras. Ao final do ensaio, a biela foi cortada para extração de corpos-de-prova menores. Estes corpos-de-prova foram submetidos a microscopia por feixe de íons feita em um FIB (Focused Ion Beam Scanning Electron Microscope) e a uma espectroscopia RAMAN para caracterizar os óxidos superficiais presentes. Griza, S. et al. (1) apresentam uma análise para identificar a causa da falha de uma biela convencional de motor diesel automotivo. Foi feita a conexão entre a 
análise de elementos finitos e a análise de falha para avaliar a relação entre a força de aperto e a propagação da trinca nos parafusos da biela. Foram propostas alterações no projeto para evitar falhas futuras. Fukuda, S. et al. apresentam a análise do método de ruptura do mancal da biela no processo de fabricação e as dificuldades de utilização dos aços convencionais que se adequam à fabricação e são inferiores quanto a resitência à fadiga. Desenvolvem um aço liga especial para bielas convencionais com alta resistência a fadiga que permite a fabricação por ruptura do mancal, sem dificuldades. Chen, N. et al. apresentam as características de resistência que uma biela de motor diesel deve ter para suportar as altas cargas. Para atingir tais características a têmpera em óleo não é suficiente. A simples têmpera em meio aquoso implica na possibilidade da ocorrência de trincas. Medem e calculam os coeficientes de transmissão de calor de diversos fluídos de têmpera e o processo de têmpera das bielas é simulado pelo método dos elementos finitos para determinação dos parâmetros do processo. Rabb, R. (4) apresenta a análise de falha por fadiga de uma biela de motor diesel de velocidade média. As dificuldades de construção do modelo de elementos finitos detalhado, incluindo as não linearidades importantes, são apresentadas. O modelamento e simulação e os testes laboratoriais de fadiga possibilitaram o desenvolvimento de um projeto melhorado da biela.

\section{METODOLOGIA}

\subsection{Modelamento e Simulação}

O modelo tridimensional da junta objeto do trabalho é mostrado na Figura 1.

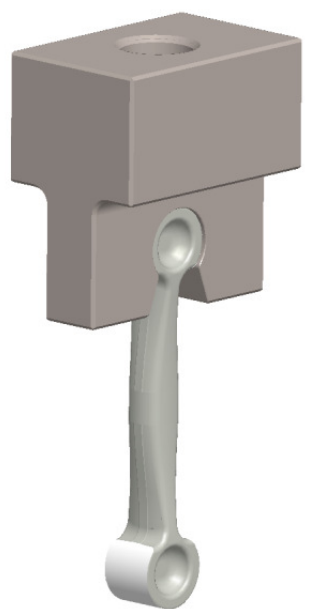

Figura 1- Modelo tridimensional da junta

As Figuras 2 a 11 indicam as condições de contorno e os resultados da simulação. As especificações dos materiais utilizados na simulação foram:

\section{Biela:}

- Densidade: $7,82.10^{-6} \mathrm{~kg} / \mathrm{mm}^{3}$

- Módulo de Young: $200 \mathrm{GPa}$

- Poisson: 0,3

- Limite de resistência: $1400 \mathrm{MPa}$

- Limite de escoamento: $1260 \mathrm{MPa}$

- Limite de fadiga: $490 \mathrm{MPa}$
Garra:

- Densidade: $7,85.10^{-6} \mathrm{~kg} / \mathrm{mm}^{3}$

- Módulo de Young: $200 \mathrm{GPa}$

- Poisson: 0,3 


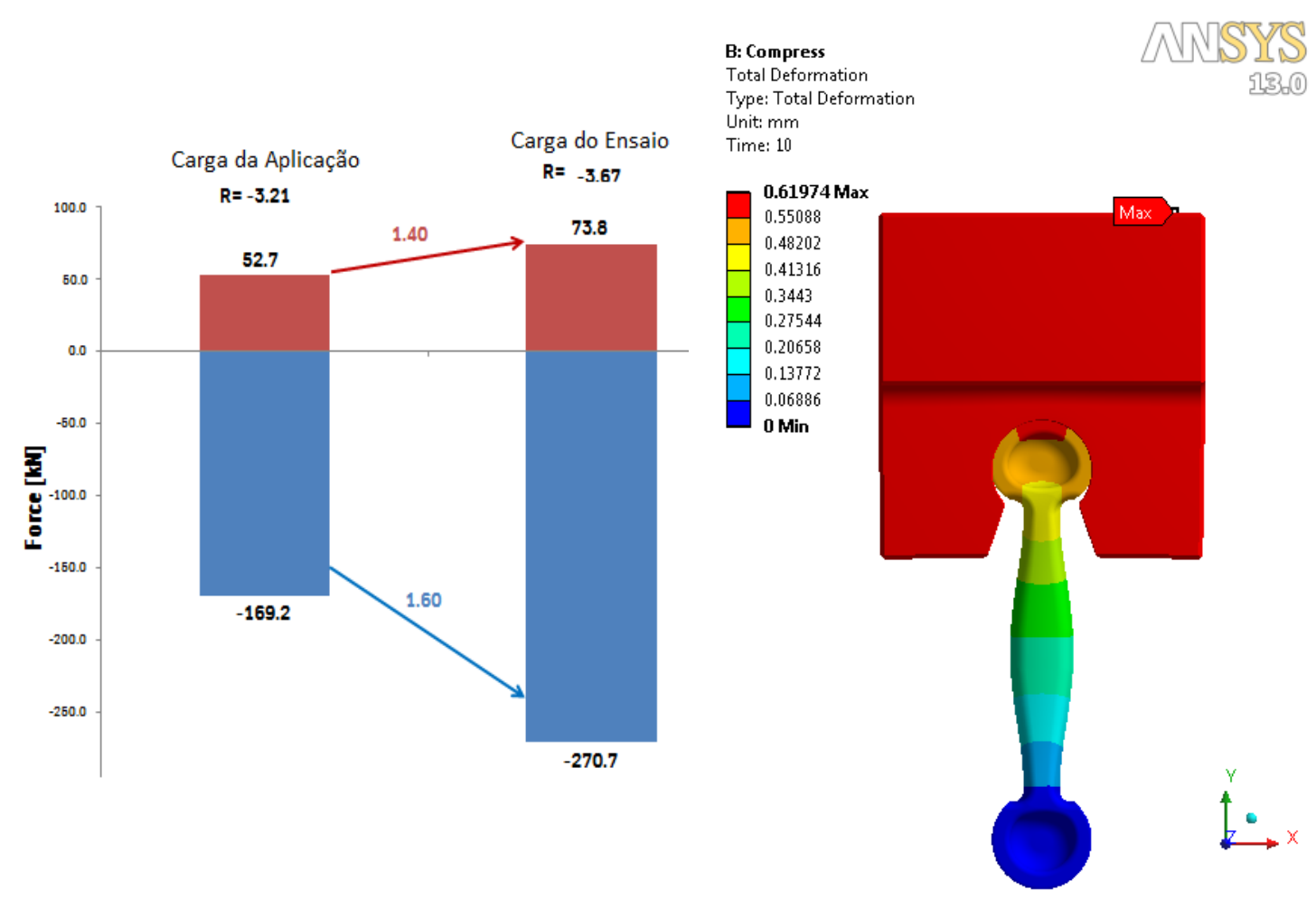

Figura 2- Cargas da aplicação típica e do Figura 3- Deformação total no ciclo de ensaio simulado

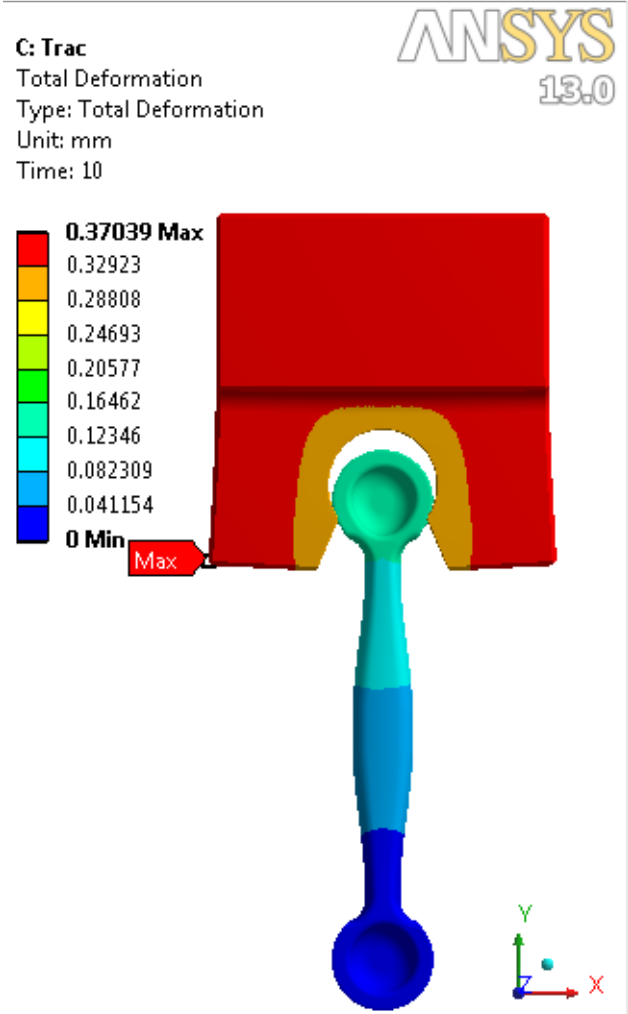

compressão

B: Compress

Directional Deformation_ $x$

Type: Directional Deformation (XAxis)

Unit: $\mathrm{mm}$

Global Coordinate System

Time: 10

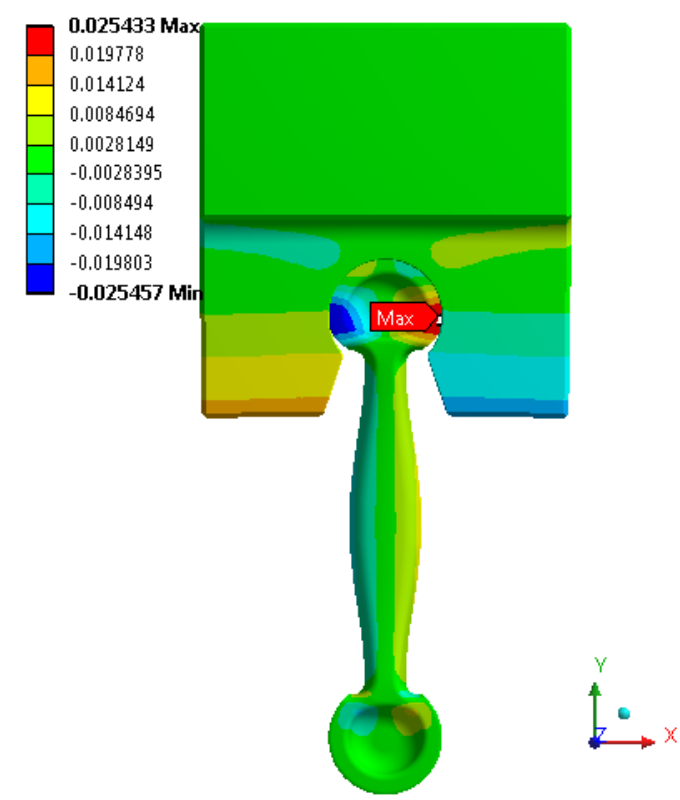

Figura 4- Deformação total no ciclo de tração

Figura 5- Deformação em compressão na direção do eixo $\mathrm{x}$ 


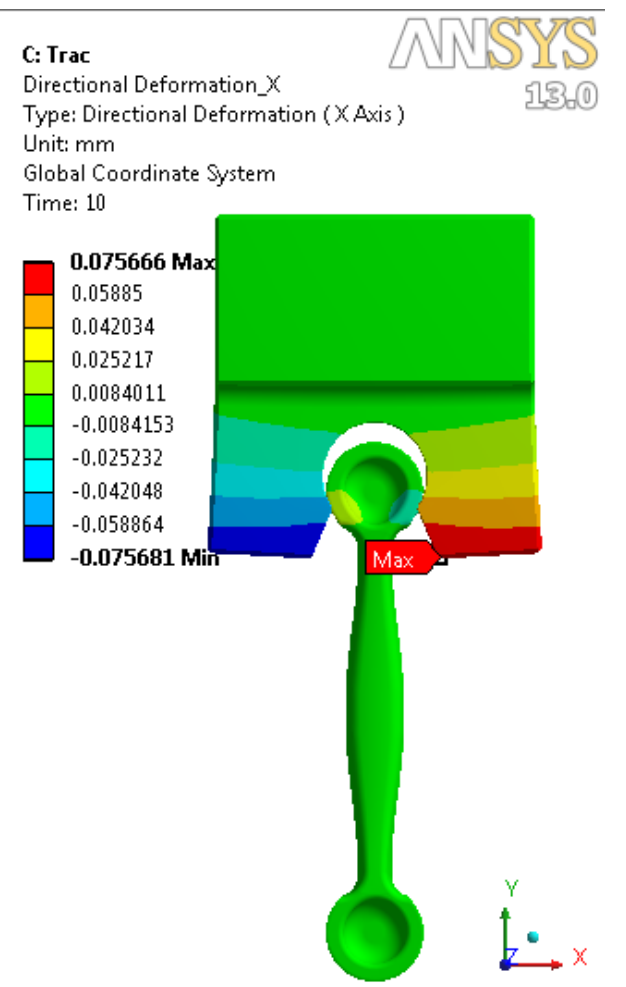

Figura 6- Deformação em tração na direção do eixo $\mathrm{x}$

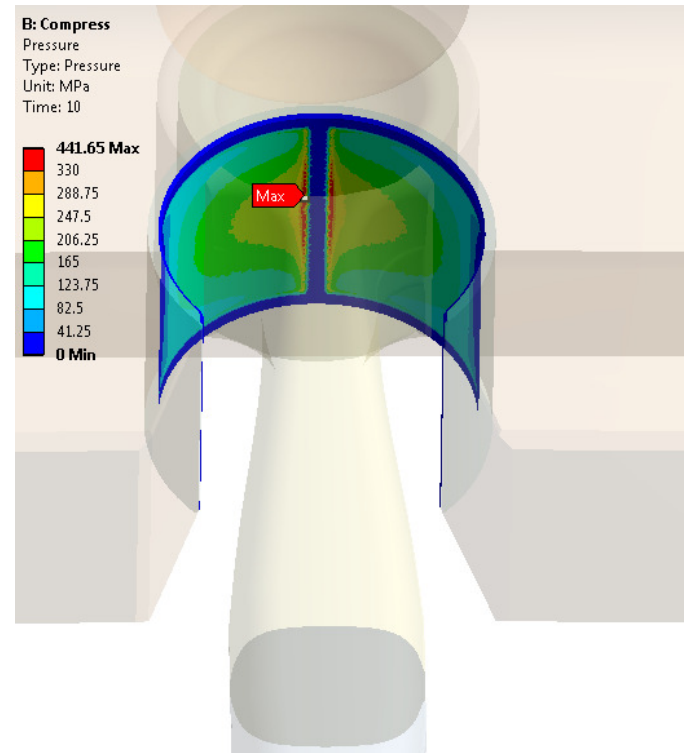

Figura 8- Pressão de contato em compressão
Type: Equivalent (von-Mises) Stress Unit: $\mathrm{MPa}$

Time: 10

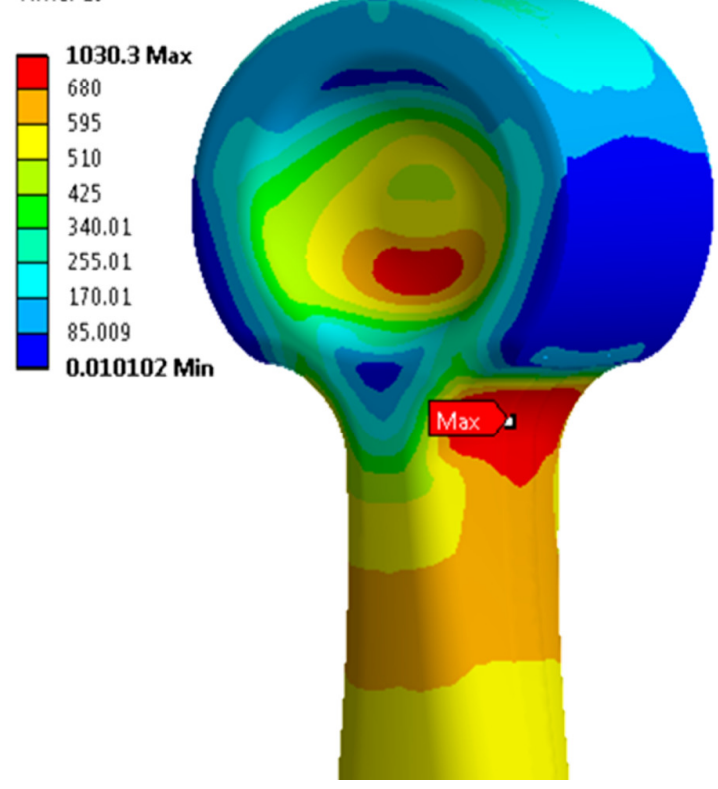

Figura 7- Tensões em tração da biela

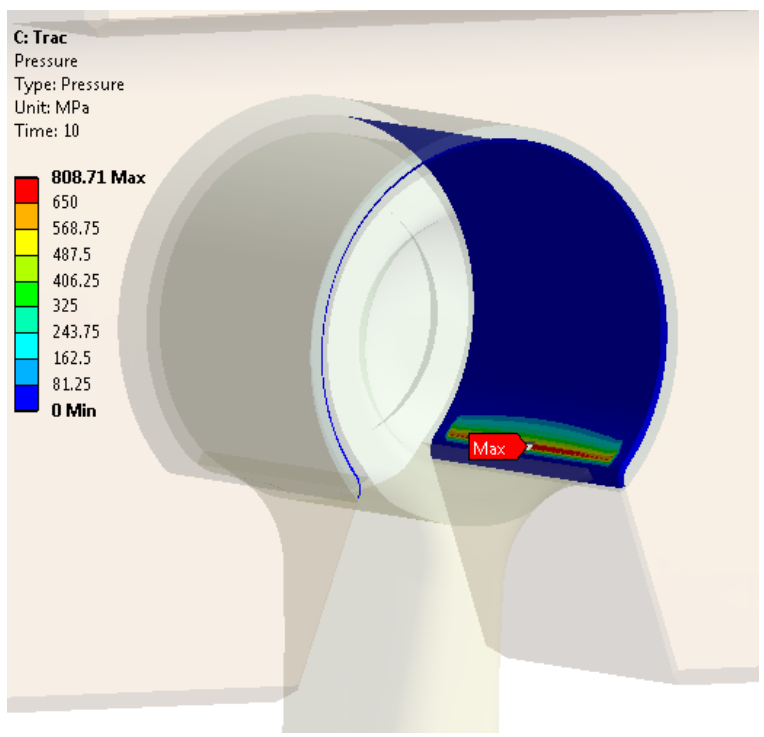

Figura 9- Pressão de contato em tração 
TMIN $=.890654$

TMAX $=4$

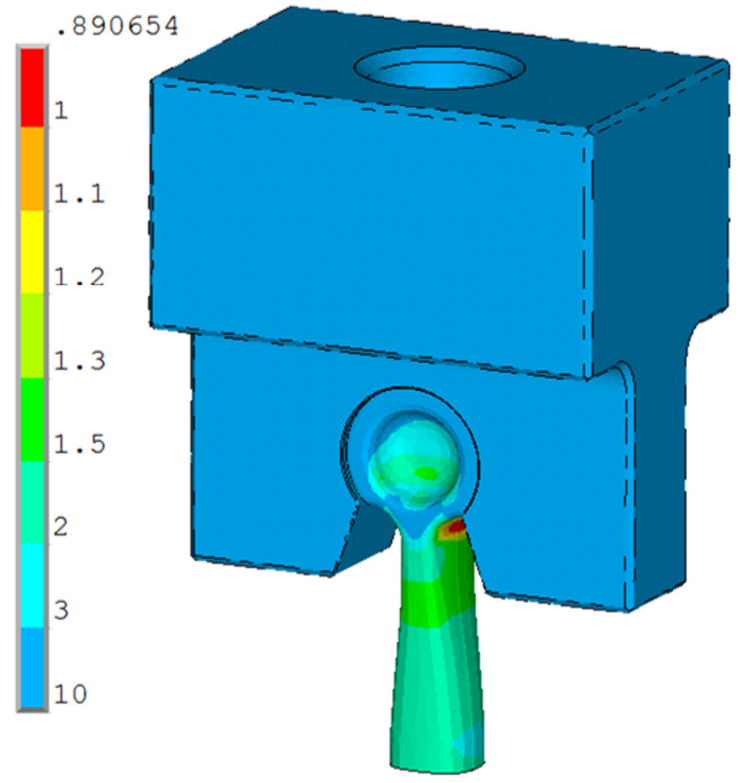

Figura 10- Resultado da análise de fadiga do conjunto

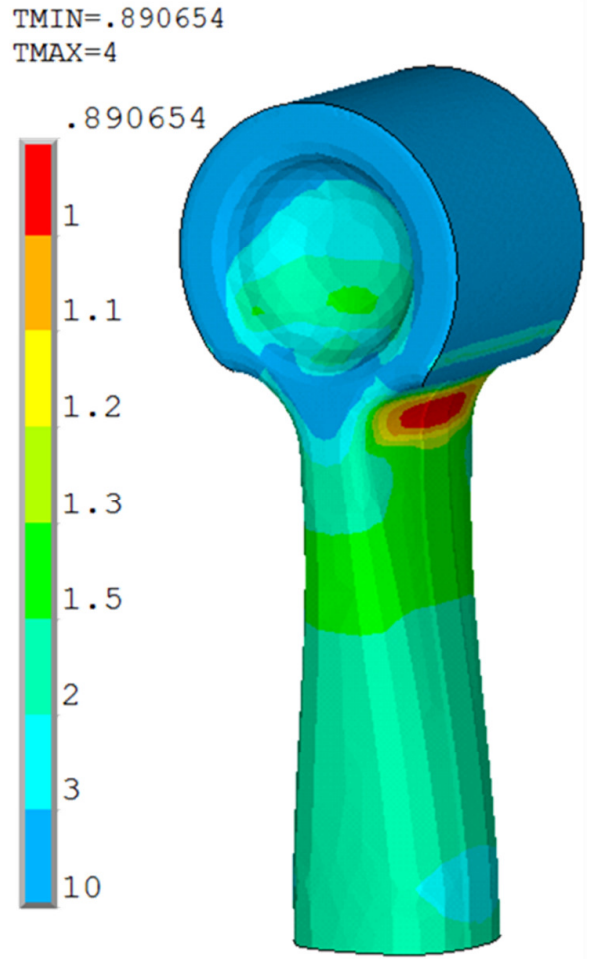

Figura 11- Resultado da análise de fadiga da biela

De acordo com os resultados mostrados nas Figuras 10 e 11, o coeficiente de segurança na região de menor secção ficou abaixo da unidade. Por este motivo decidiu-se realizar os ensaios de laboratório com cargas $10 \%$ menores do que as mínimas indicadas, seguindo o método "staircase" com $5 \%$ de degrau da força alternada $(172,25 \mathrm{kN})$, isto é $8.6125 \mathrm{kN}$, conforme Figura 12.

\section{Conrod Staircase Estimation \\ Loads Changing with constant \\ $R=-3.67$}

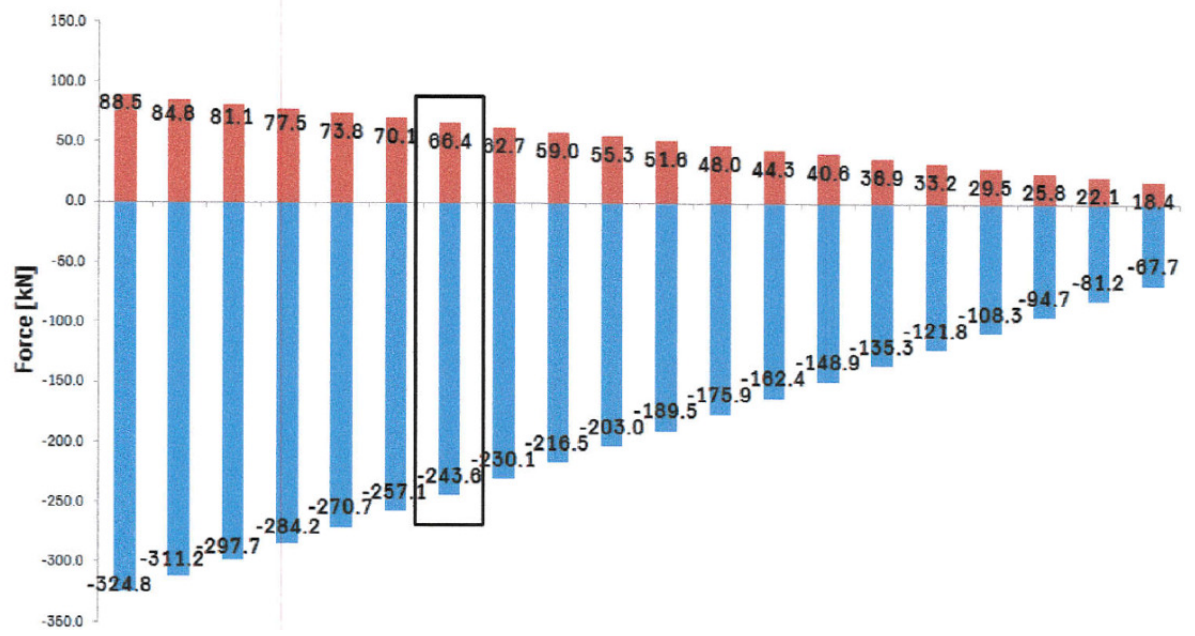

Figura 12- Escolha da forças na realização do ensaio $(\mathrm{R}=-3,67)$ 


\subsection{Definições do Ensaio de Laboratório}

O ensaio de fadiga foi desenvolvido para aplicação de uma força alternada de forma de onda senoidal. Esta onda variou entre valores máximos de tração e de compressão. Os valores máximos foram fixados a partir de considerações de uma aplicação automotiva típica.

O equipamento de ensaio foi uma máquina hidráulica servo-controlada com $500 \mathrm{kN}$ de capacidade de tração e de compressão, controlador Flextest 60 e unidade SilentFlo 505.30.

Foram aplicados 10.000 .000 de ciclos de força ao conjunto, com os valores máximo e mínimo das forças conforme escolha da Figura 12. A cada 1.000.000 de ciclos completados, o ensaio era interrompido e o conjunto de pino e garras era desmontado para análise. Foram feitas análises dimensional e tribológicas das superfícies em contato e documentação fotográfica das superfícies desgastadas.

O ensaio incorporou em seu projeto um sistema de lubrificação com bicos aspersores dirigidos às regiões das juntas superior e inferior. Este sistema utilizava o mesmo lubrificante da aplicação automotiva típica, ou seja óleo SAE 15W40 API CS/CS2. O óleo era recirculado através de uma bomba elétrica e filtrado pelo mesmo modelo de filtro da aplicação automotiva típica.

\section{MONTAGEM DO ENSAIO EM LABORATÓRIO}

Antes de iniciar os ciclos de fadiga, o conjunto foi tracionado com $88 \mathrm{kN}$ e nesta condição os anéis de pré tensão foram apertados manualmente. Após o aperto dos anéis a força de tração do conjunto foi retirada.

Vistas de modelos tridimensionais da montagem do conjunto de peças na máquina de ensaio são mostradas nas Figuras 13 e 14.

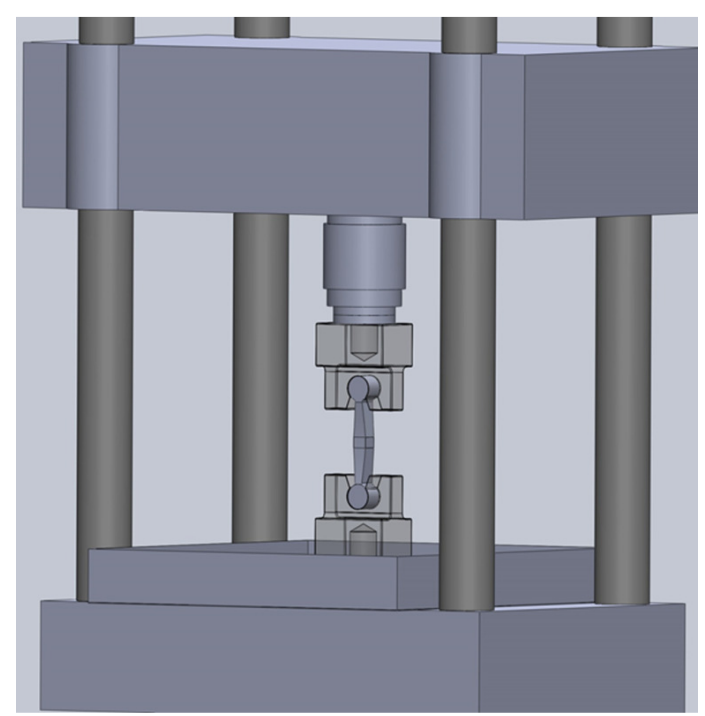

Figura 13 - Representação 3D da mesa de ensaio 


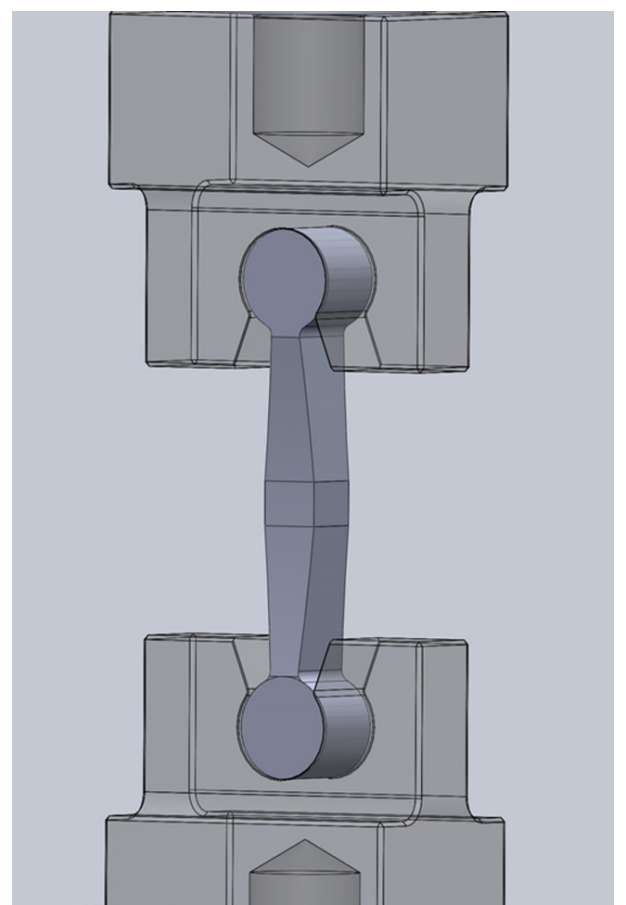

Figura 14 - Detalhe 3D do conjunto: garra superior, garra inferior e pino

O conjunto de bicos articulados de lubrificação (aspersores) com regulagem individual de vazão é mostrado na Figura 15 e em detalhe na Figura 20.

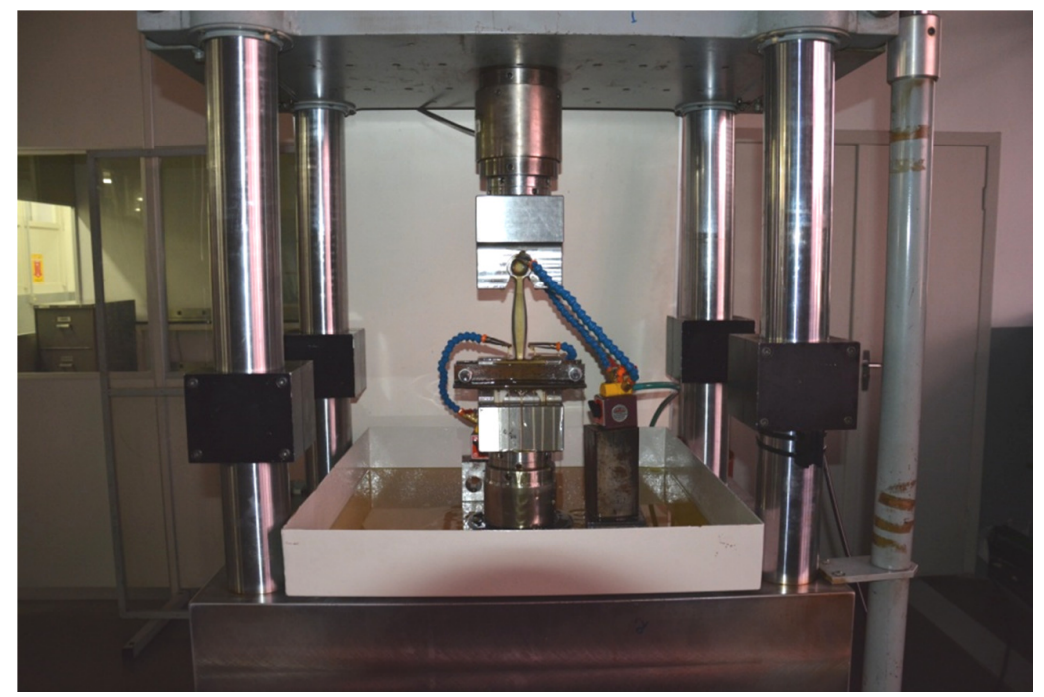

Figura 15 - Mesa de ensaio hidráulica servo-controlada

Uma unidade de lubrificação com acionamento elétrico é mostrada na Figura 16 e um detalhe da unidade de filtração mostrado na Figura 17. 


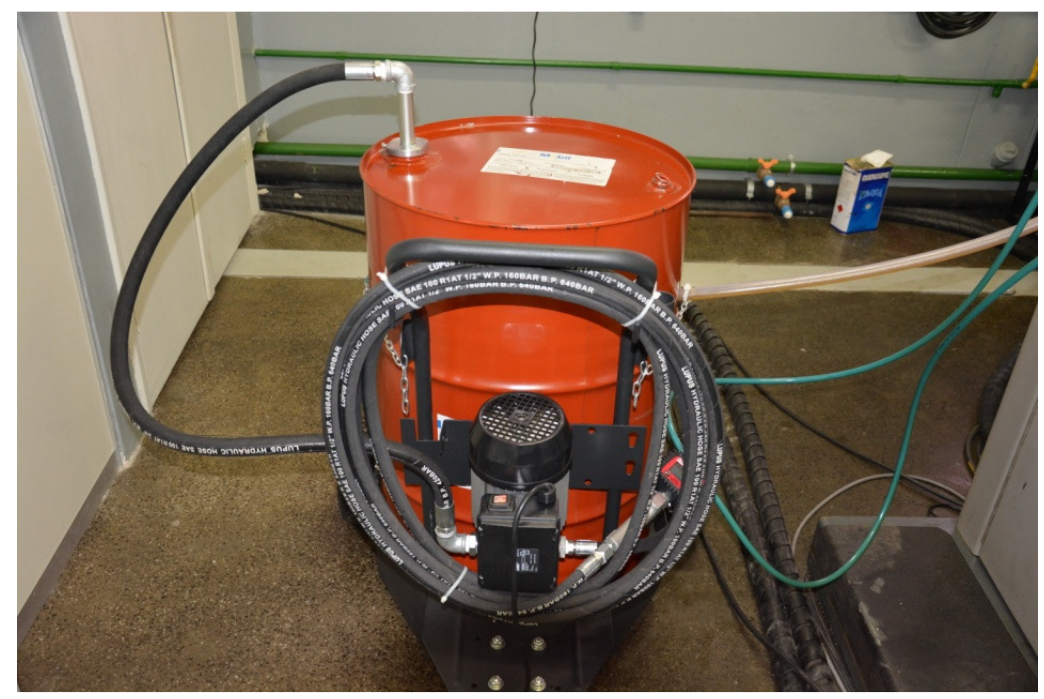

Figura 16 - Unidade de lubrificação

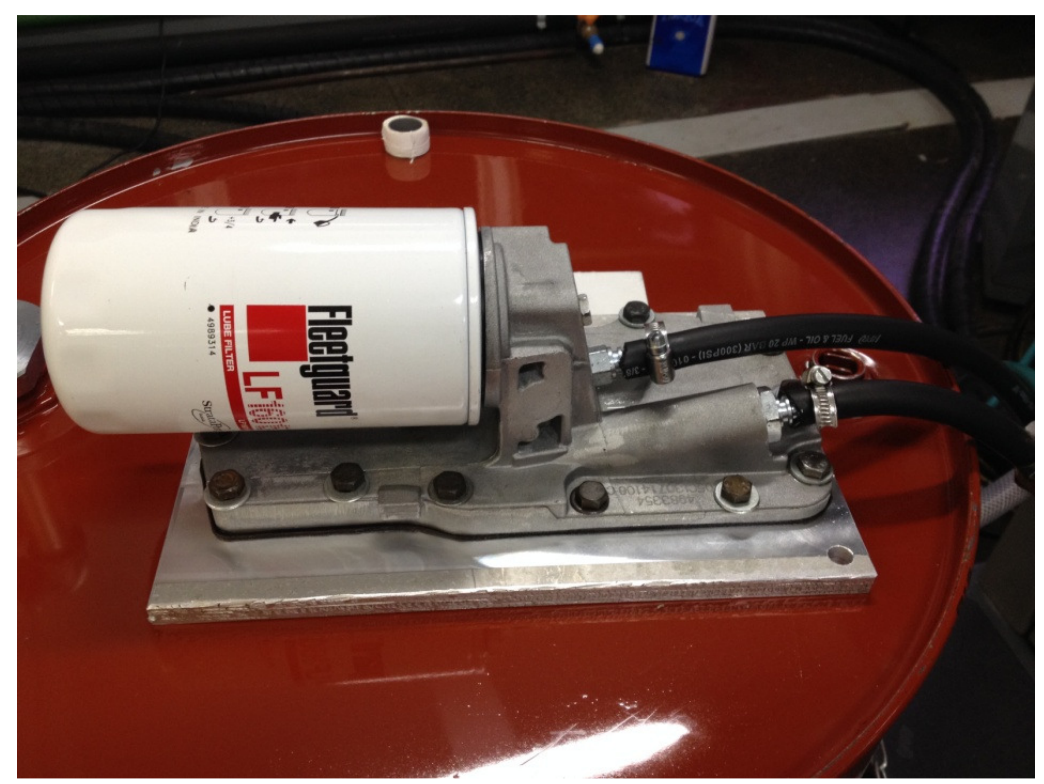

Figura 17 - Unidade de filtração de óleo

\section{EXECUÇÃO DO ENSAIO}

A montagem detalhada do ensaio é mostrada na Figura 20.

No ensaio foram aplicadas forças cíclicas uniaxiais senoidais, alternadas entre os valores nominais de $66,4 \mathrm{kN}$ (tração) e $-243,6 \mathrm{kN}$ (compressão). Uma tela representativa do programa de controle é mostrada na Figura18. 


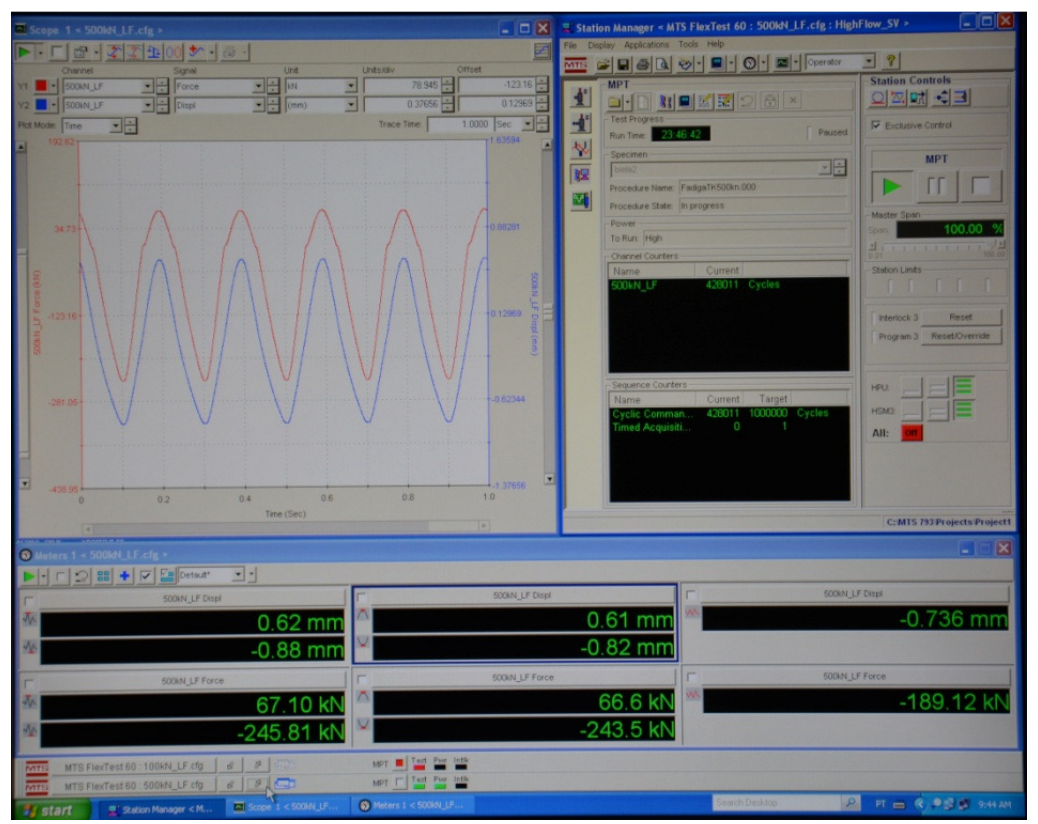

Figura 18 - Tela do programa de controle

No conjunto foram aplicados 10.000 .000 de ciclos, sendo que a cada milhão completado, o ensaio era pausado e as peças desmontadas e verificadas em relação a sua condição superficial, nas regiões onde ocorreu desgaste, através de lupa estereoscópica computadorizada, efetuando-se um registro fotográfico.

Foi utilizado um sistema de identificação que é mostrado na Figura 19. Isto foi feito para que as sucessivas montagens das peças, a cada milhão de ciclos, fossem feitas exatamente da mesma maneira e os pares das superfícies de desgaste permanecessem sempre os mesmos.

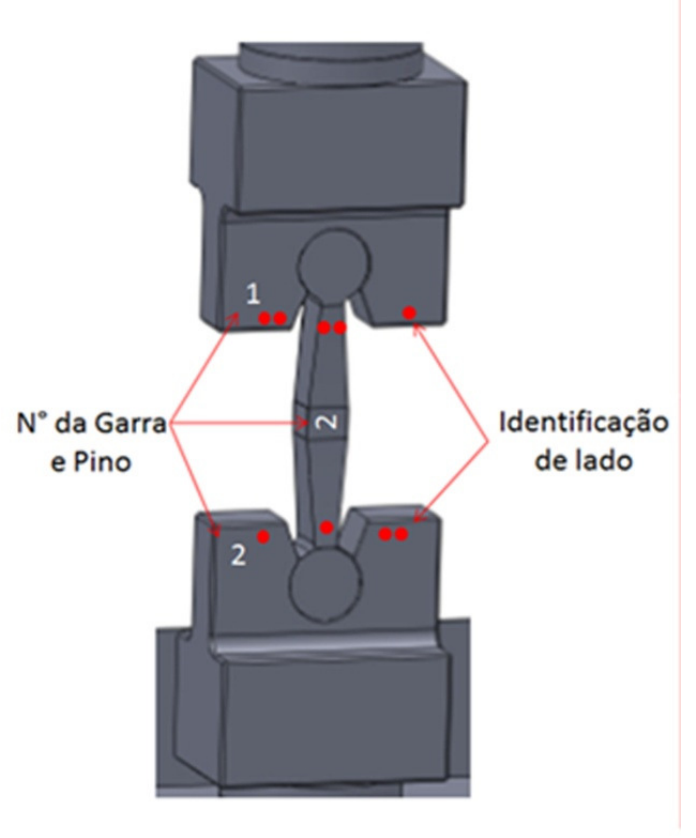

Figura 19 - Sistema de identificação usado para as sucessivas montagens 


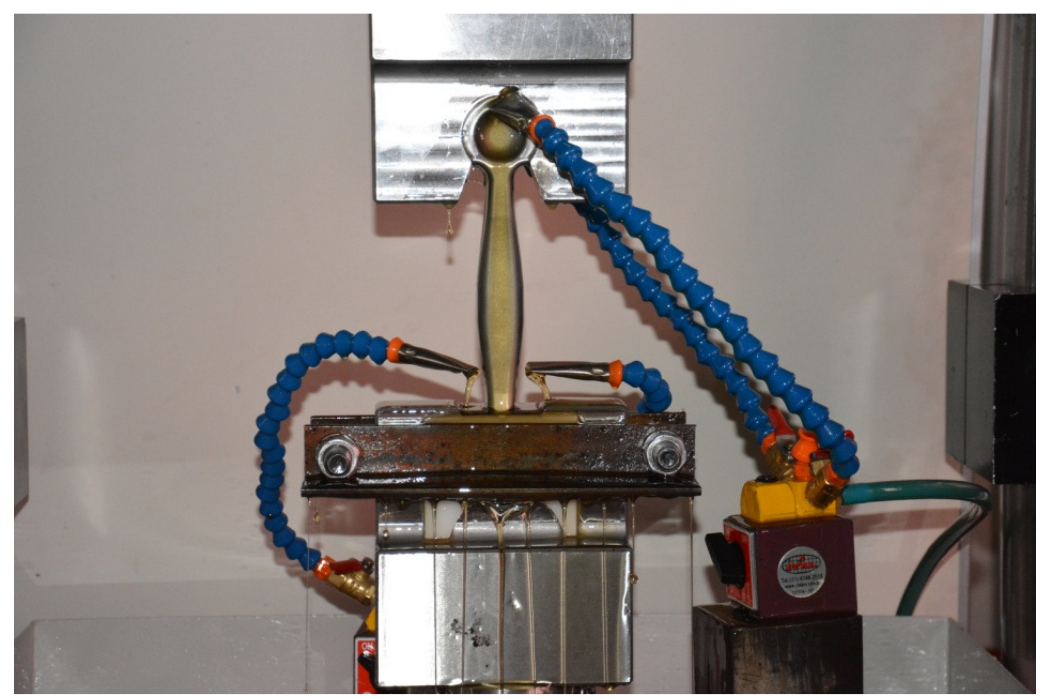

Figura 20 - Detalhe do ensaio

\section{ANÁLISES e RESULTADOS}

A "biela" suportou a aplicação de 10.000.000 de ciclos no ensaio de fadiga. As Figuras 21 e 22 mostram a "biela" após o ensaio. A Figura 22 mostra aspectos da "biela" onde se percebe o desgaste na região de máxima compressão nas duas extremidades.

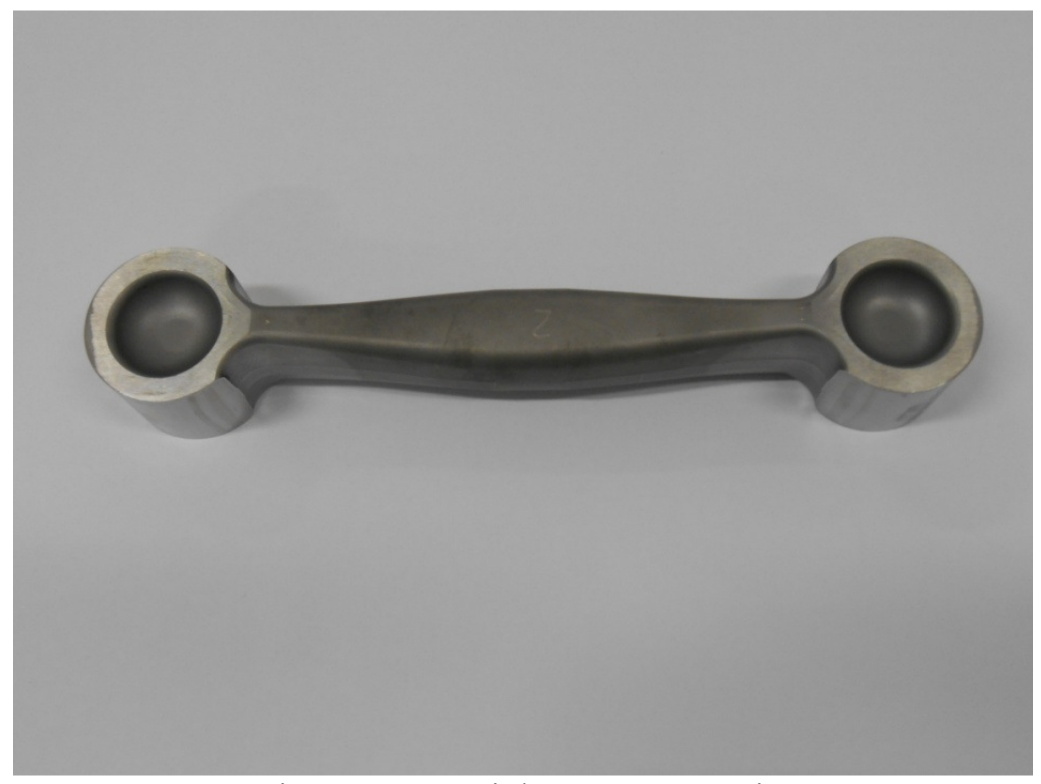

Figura 21 - "Biela" após o ensaio 

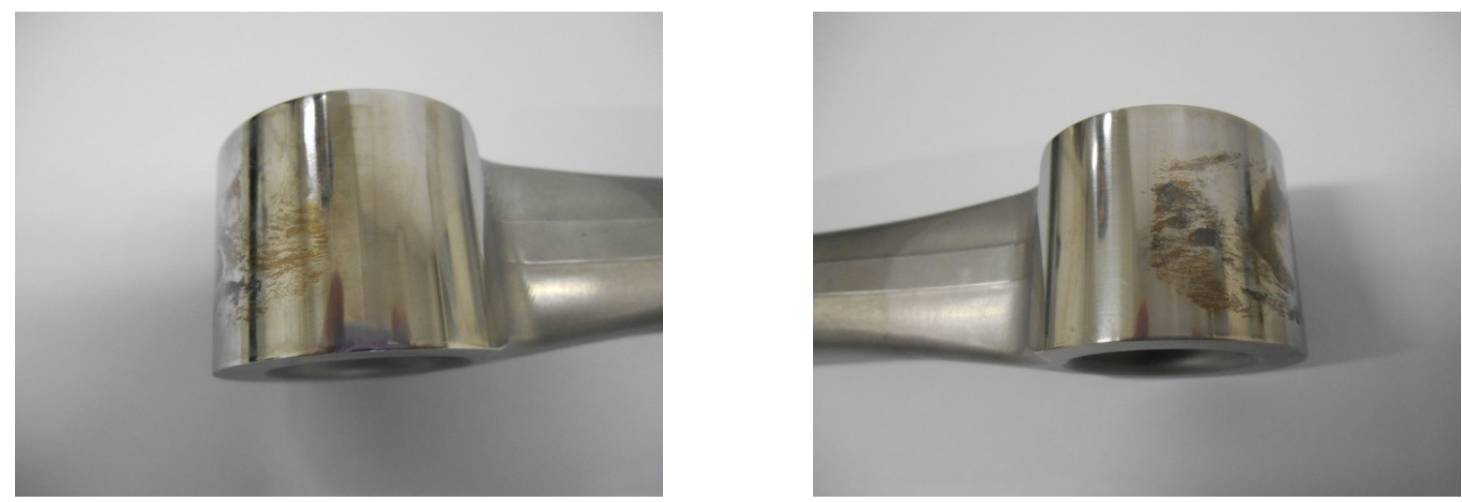

Figura 22 - Extremidades da "biela" após o ensaio mostrando marcas de desgaste

As Figuras 23 e 24 exemplificam dois aspectos superficiais: com zero ciclos e com 5.000.000 de ciclos.

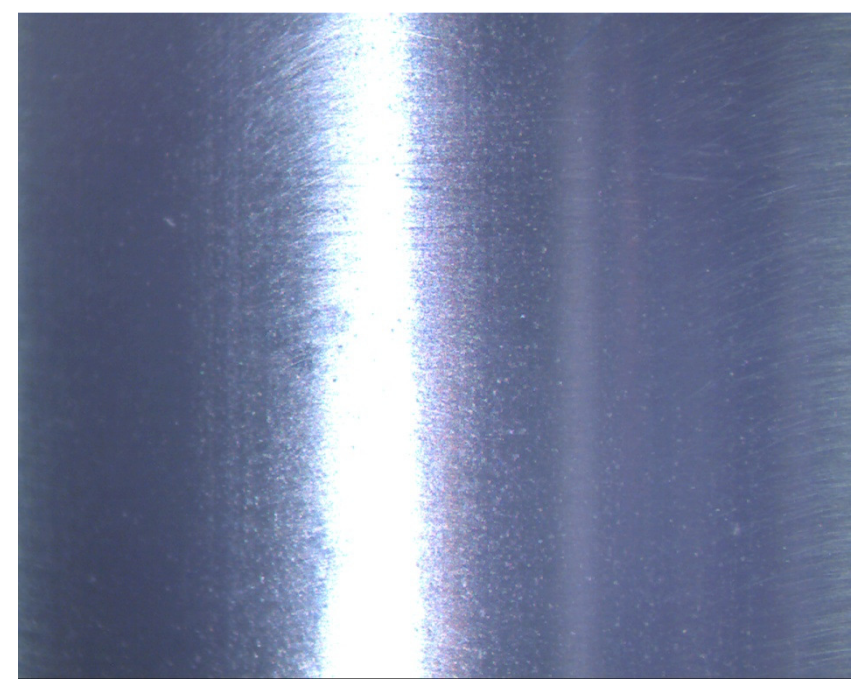

Figura 23 - Aspecto da superfície antes do ensaio

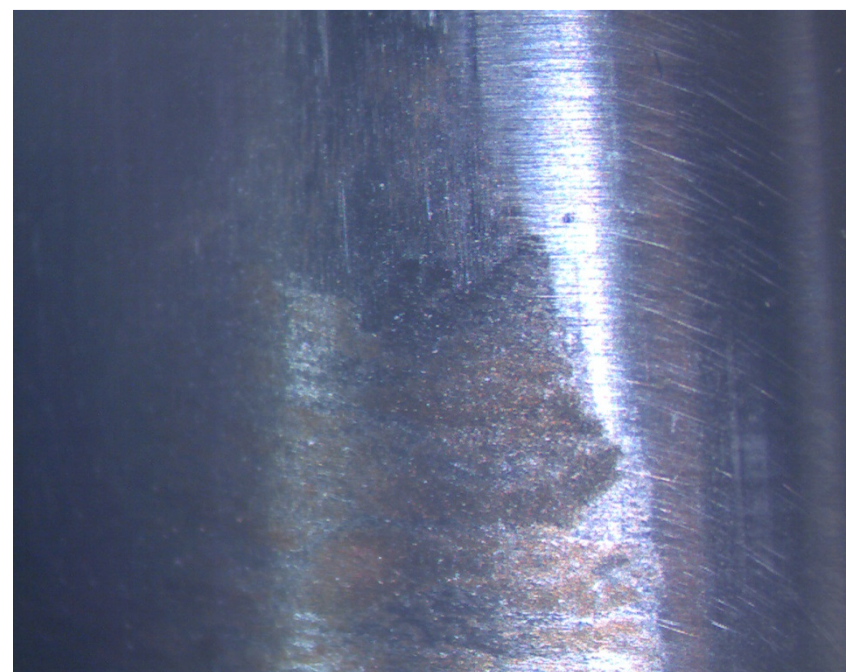

Figura 24 - Aspecto da superfície após 5 milhões de ciclos 
As Figuras 25 e 26 mostram o aspecto da seção transversal da microestrutura do material por feixe de íons evidenciando a presença de martensita revenida maclada. A Figura 25 mostra uma camada de óxidos na superfície. A Figura 26 não apresenta a camada de óxidos.

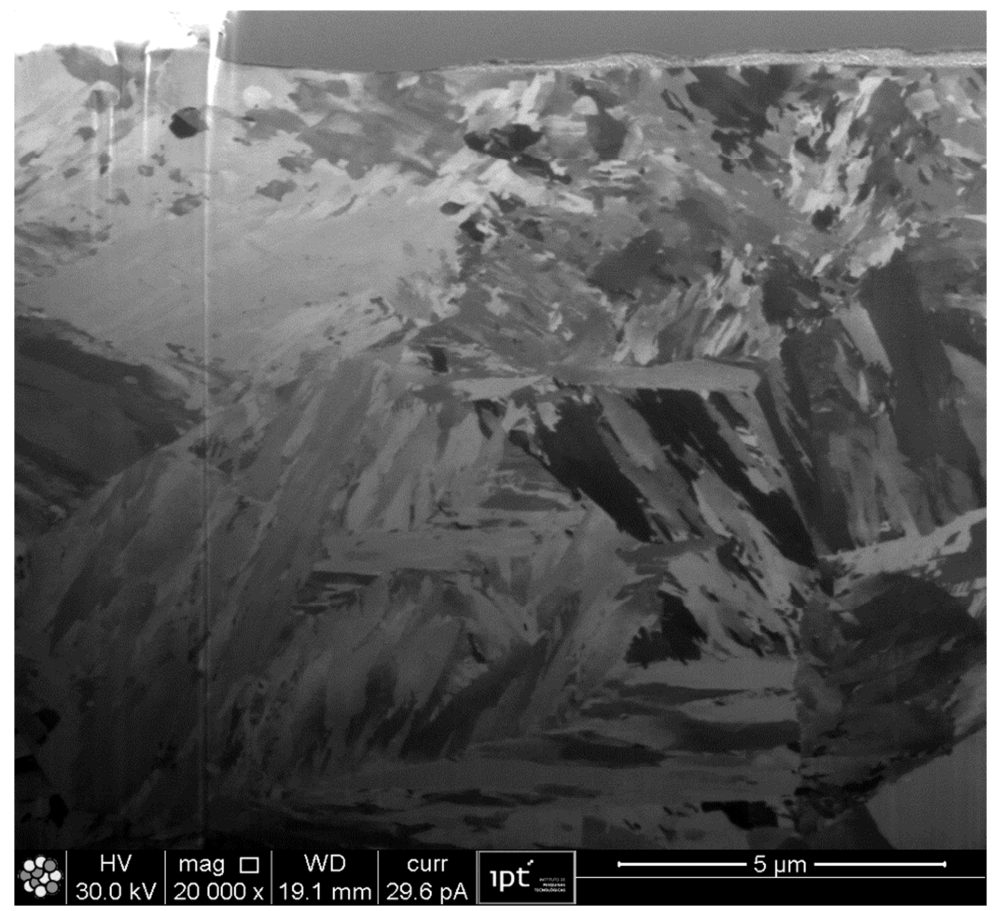

Figura 25 - Aspecto da microestrutura da seção transversal após 10.000 .000 de ciclos mostrando tribo filme de óxido

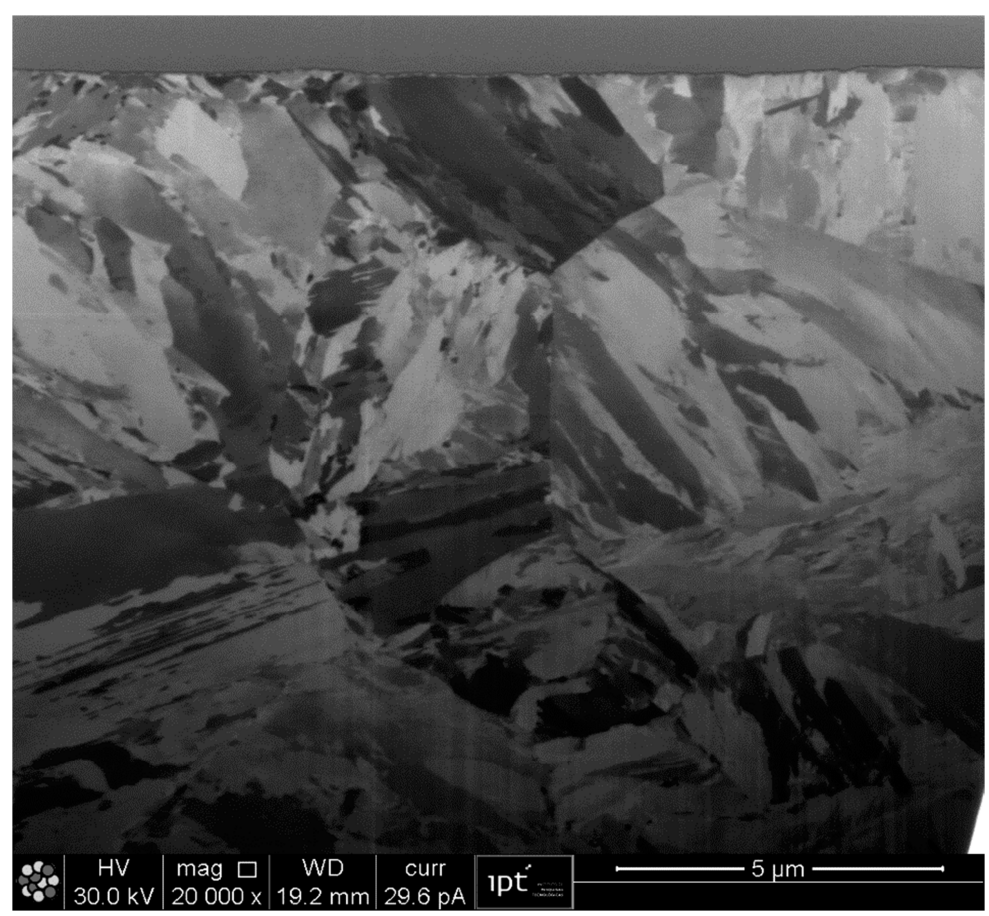

Figura 26 - Aspecto da microestrutura da seção transversal após 10.000.000 de ciclos mostrando uma região da superfície sem óxido 
A Figura 27 mostra o resultado da espectroscopia RAMAN com dois espectros de referência: da hematita e da magnetita e a correspondência parcial nas duas regiões apresentadas indicando a presença destes óxidos.

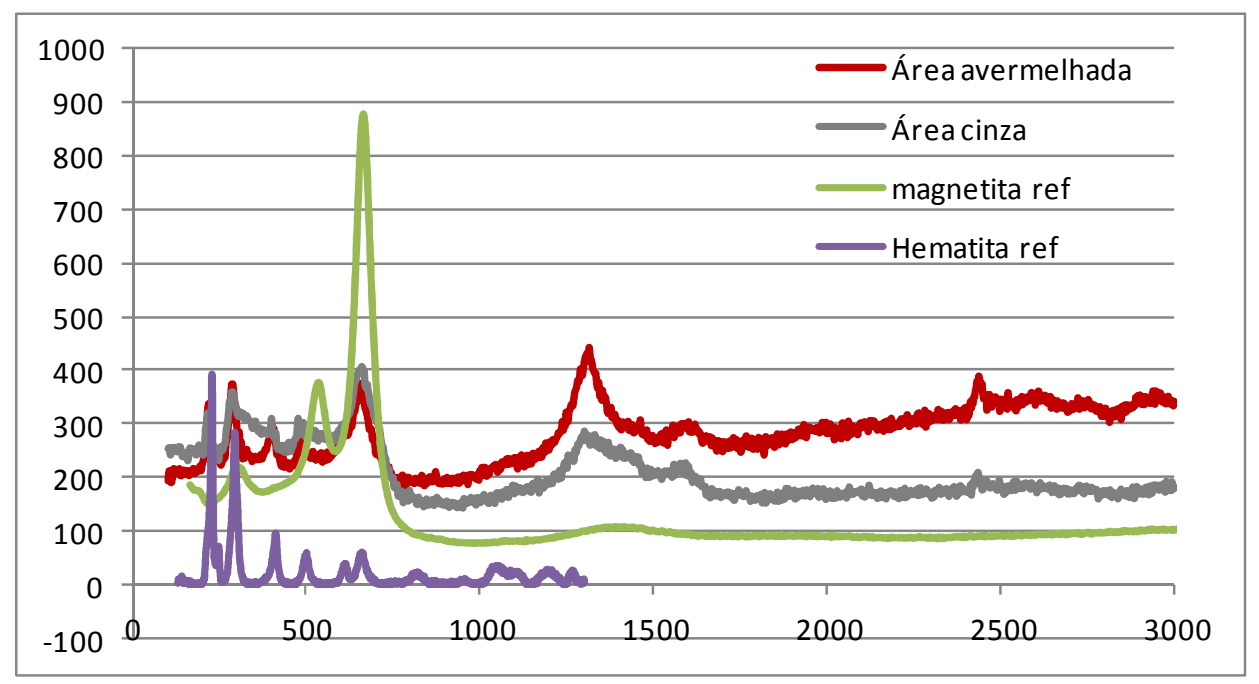

Figura 27 - Espectroscopia ótica RAMAN

\section{CONCLUSÕES}

A simulação virtual do ensaio apontou um fator de segurança inferior a 1 na região crítica de menor seção transversal. Portanto as cargas utilizadas neste primeiro ensaio foram $10 \%$ inferiores às da simulação numérica, porém superiores às da aplicação real.

A biela ensaiada suportou a aplicação de 10.000 .000 de ciclos. O desgaste das superfícies das juntas mostrou-se normal.

A microscopia FIB das seções transversais mostrou uma estrutura martensítica com a presença de óxidos na superfície.

A espectroscopia RAMAN mostrou a formação de tribo-filme de óxidos. Houve um provável aquecimento localizado nas superfícies articuladas. Melhoramentos na lubrificação nos próximos ensaios devem ser implementados.

\section{REFERÊNCIAS}

[1] RABB, Roger. Fatigue Failure of a Connecting Rod. Engineering Failure Analysis, Wartsila Diesel International Ltd, PO Box 244, FIN - 65101, Vassa, Finland, v. 3, No. 1, p. 13-28, 1996.

[2] CHEN, Nailu; HAN, Lizhan; ZHANG, Weimim; HAO, Xiaowei. Enhancing mechanical properties and avoiding cracks by simulation of quenching connecting rods. Materias Letters, School of Materials Science and Engineering, Shanghai Jiaotong University, Shanghai 200240, China, v. 61, p. 3021-3024, 2007. 
[3] FUKUDA, Shinsaku; ETO, Hirohito. Development of fracture splitting connecting rod. JSAE Review, Materials Development Sec. No. 1, Vehicle Research \& Experiment Dept., Engineering Research and Experiment, Isuzu Motors Limited, 3-25-1, Tono-machi,

Kawasaki-ku, Kawasaki-shi 210-8524, Japan, v. 23, p. 101-104, 2002.

[4] GRIZA, S.; BERTONI, F.; ZANON, G.; REGULY, A.; STROHAECKER, T.R. Fatigue in engine connecting rod bolt due to forming laps. Engineering Failure Analysis,

Departamento de Metalurgia, Universidade Federal do Rio Grande do Sul, Av. Osvaldo

Aranha, 99/610, Porto Alegre 90035 190, Brazil, v. 16, p. 1542-1548, 2009. 